\title{
The Competency Development of Multimodal Transportation Management for Logistics Professional in Thailand
}

\author{
Anothai Ngamvichaikit
}

\begin{abstract}
This research aimed to develop the competency multimodal transportation management in logistics professionals of Thailand. The research methodology used qualitative approach to conduct focus group with entrepreneurs of logistics firms in Thailand. The transcript was analyzed by functional analysis. The results suggested that the key functions of multimodal transportation management composites of 3 functions; 1) offering multimodal transportation services, 2) managing multimodal transportation services and 3) developing multimodal transportation services. The units and elements of competency were extracted and found the 10 units of competency (UOC) and 27 elements of competency (EOC). The detailed findings were validated with the panel of 20 international freight forwarding experts and association representatives. Final competency model was transferred to assessment tools which were tested with practitioners. Further training and assessment with certification process will be executed with logistics professionals to improve the effectiveness of managing multimodal transportation in Thailand.
\end{abstract}

Index Terms-Multimodal transportation, logistics, competency, Thailand.

\section{INTRODUCTION}

The transportation service is a critical business and important to the economic and social demand especially in the era of borderless world. Efficient and timely logistics of raw materials and finished goods from geographically distant locations between sellers and customers provoke for freight forwarding service [1]. Regarding commercially global integration, the conventional single mode of transportation cannot provide an all-time feasible solution, necessitating other combining means to support especially long haul distribution and door-to-door services. Multimodal transportation is defined as the carriage of goods by two or more modes of transport, under single responsible service provider for the entire transportation [2]. The service provider can outsource the contract of partial, or entire services, of the carriage to other carriers and manage overall

Manuscript received December 25, 2016; revised January 30, 2017 (Write the date on which you submitted your paper for review.) This work was supported in part by the Thailand Professional Quality Institute (Public Organization) under Grant.

A. N. Author is with the Sukhothai Thammathirat Open University, Nonthaburi, Thailand (e-mail: anothai.ne@gmail.com). performance of integrated service for consignee. Multimodal transportation requires high skill of managing the carriage according to combining risks of route places a negative effect toward the quality of transportation, in terms of cost and timeliness of delivery or damaged freight [3]. Additionally, the guideline for managing multimodal transportation still not be clear, some scholars recommend to use quantitative model [4], [5] whereas some scholars advice to minimize risk [3]. Regardless to higher risk of transportation, the mandatory of multimodal transportation still be agenda for service providers to handle the freight with unique competency.

Additionally Asian countries including Thailand, Malaysia, Singapore, Philippines, Burma, Cambodia, Vietnam and Laos have integrated toward Asian Economic Cooperation since 2015. Effective multimodal transportation significantly response with regional trade coordination and reduce the overall logistics cost. The human capability remains key factor toward multimodal transportation management [6] according to higher risk as well as higher time and cost saving from combined modes of transportation. Developing logistics professional for multimodal transportation management become privacy to cope with rising trend of global sourcing and production.

This research proposes a logistics functional analysis for the multimodal transportation management competency in Thailand. The paper is structured in 5 sections starting from introduction as section I, a literature review in next Section II, a research methodology in Section III, result in Section IV and finally conclusion and discussion in Section V.

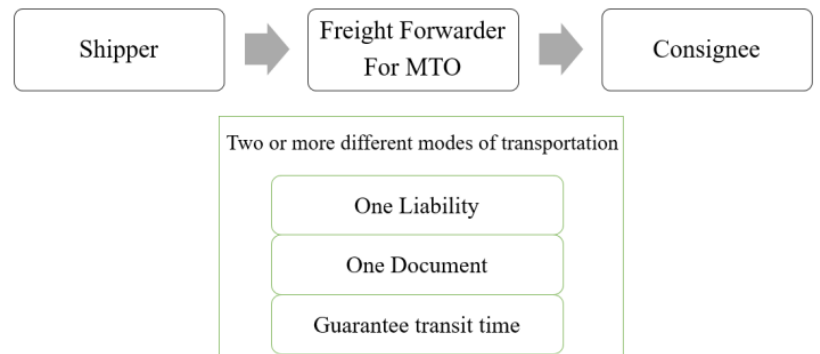

Fig. 1. Conceptual model of multimodal transportation management Source: Adapted from Hayuth (1987) [9].

\section{LITERATURE REVIEW}

The literature review consists of 4 topics related with competency development of multimodal transportation management in Thailand; multimodal transportation management, competency, functional analysis, competency research in multimodal transportation management. 


\section{A. Multimodal Transportation Management}

Multimodal transportation is defined as the transportation of goods by using a sequence of two or more various modes of transportation [7]. The means of transportation can be combined among waterway, road, rail, air or vessel. As such, examples of multimodal transportation are mostly long-distance logistics services including regional delivery. Similar terms like combined transportation or through transportation intermodal transportation are all used for end-to-end linkage movement in which two or more different transportation modes [8].

Multimodal transportation management requires high skill of planning. Logistics professionals who handle multimodal delivery can approach to integrate in operation, management and control of transportation, so that delivery from origin to destination is possibly shorter.

\section{B. Competency}

Competency is termed for the human capability to utilize a set of relevant knowledge, skills, and abilities to perform in critical tasks and deliver the desirable outcome in a defined job profiling [10]. Competence is defined as the quality of performing functionally adequate in the specified tasks and position with the requisite knowledge (cognitive attributes), skill (psychomotor attributes) and attitudes (affective attributes), including other attributes associate with job performance [11]-[13]. Company must support for competency development to ensure their employee adequate knowledge, skill and attitude appropriated to job performance. Competency is observable and behavioral capabilities that are required to perform job responsibilities and deliver standard outcome [14], [15]. Clearly industry, organization, government and education institute investigate and create for competency modeling to develop human resource for successful business.

\section{Competency Composition}

Competency is a combination of practical and theoretical knowledge, cognitive skills, behavior and values used to improve performance of employee role and responsibilities. There are 3 compositions for competency.

1. Knowledge: Theoretical or practical understanding of a related subject with international freight forwarding such as international regulation, criteria to consider for international freight forwarding etc.

2. Skill: the learned ability to carry out a task with pre-determined expectation often within a given amount of time, energy, or both such as communication skill, computer skill etc.

3. Behavior attributes: the range of actions, values and beliefs demonstrated by individuals and impact positively to job performance such as positive attitude, learning motivation, team working, leadership etc.

\section{Functional Analysis}

Function analysis is competency analysis technique to define competency cascade from working process ranging from key purposes, key roles and key functions of the occupation. Next the demonstrated behaviors are categorized to be units of competency, elements of competency and performance criteria consecutively. The detailed performance criteria consist of range statement to define the boundary of work piece, evidence requirement to specify objective evidence for evaluation and skill/knowledge requirement to suggest which skill and knowledge are prerequisite for this detailed competency.

The process of develop competency based model was referred from DACUM analysis which was defined by The Center on Education and Training for Employment (CETE) as an "occupational skill profile which can be used for instructional curriculum development, training needs assessment, and competency test development[16]. The group of 10 experts was set to develop occupational standards based on competency model. The job analysis was performed to define important competency for each level of professional standards.

\section{Research in Logistics Competency}

Logistics professionals require to possess long range of business, management and technical skills [17]. Entry level of logistics must hold proportionated operational skills such as logistics planning, forecasting, whereas senior level need to use higher management related skills such as business analysis, strategic planning, people supervisory [18]. The study of clothing logistics competency [19] revealed logistics activities; customer service, transport management international logistics, order processing, packaging and inventory control and translated into logistic specific and clothing specific competencies. The study of Taiwan logistics firm identified related four logistics competencies, namely, integration and knowledge competency, customer focused logistics competency, measurement competency, and agility competency [20]. The competency research of terminal port employees also suggested for business related, management related and port logistics related competencies [21]. Among literatures related to logistics competency, there is limited empirical research on multimodal transportation competency and address for further people development.

\section{RESEARCh METHODOLOGY}

To study on multimodal transportation management competency, there are 3 relevant stakeholders in this research; academic researchers, working panel and endorsers as Fig. 2.

1. Researchers

The researchers in this study are scholar in higher educational institutes who graduated doctor degree in management science, hold professional teaching and curriculum development experience and expert in qualitative research by using focus group technique and data validation with expert panel and documents. The pre-research training about functional analysis and competency illustration has been conducted by Thailand Professional Qualification Institute (public organization) (TPQI).

\section{Working panel}

The 10 executives and managerial employees of freight companies were purposively recruited to participate in multiple rounds of focus group with multimodal transportation experience longer than 10 years and demonstrate high communication skill to depict their behavioral repertoire.

\section{Endorsers}

The endorsers composited of 20 experts in management executives from logistics association and companies such as 
Thai Transportation Association, The Customs Brokers and Transportation Association of Thailand, Thai International Freight Forwarding Association etc. were purposively selected to validate and endorse the competency of multimodal transportation management of Thailand under examination of Thailand Professional Qualification Institute (public organization).

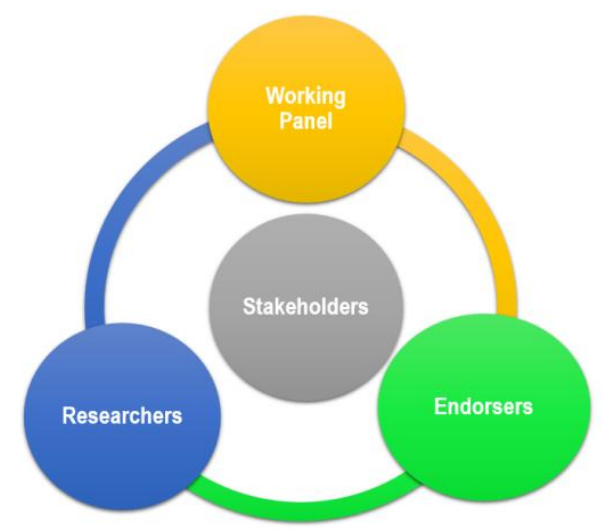

Fig. 2. Three stakeholders in this research.

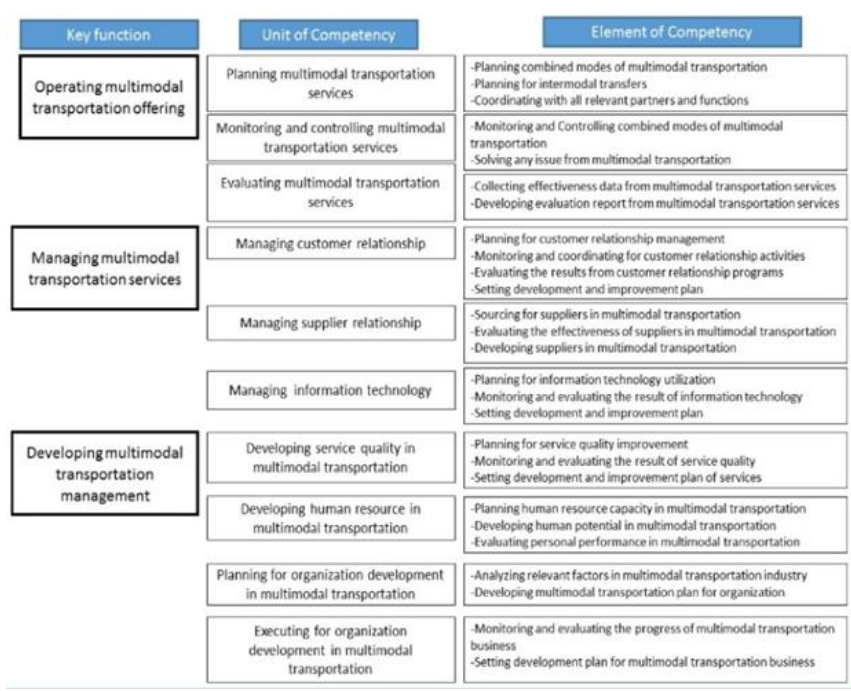

Fig. 3. The diagram of 3 key functions 10 units of competency and 27 elements of competency.

In this study, 3 steps of research process were adopted to identify competencies that are mandated for successful multimodal transportation management;

\section{A. Preparation}

1. Communicate with related stakeholders to understand the research objectives and process.

2. Recruit working panel who are expertise in managing multimodal transportation with longer than 10 years of experience and hold high communication skill.

3 Study relevant documents including

-Multimodal transportation standards in other countries which were Malaysia, British and Hong Kong standards.

-Job analysis process for developing occupational standards.

-Logistics stakeholders' role, responsibilities and regulations.

- Industry information and related literatures.

4. Propose working panel's name list toward research committees.

5. Present documentary research with research committees, related freight forwarding associations, entrepreneurs and organizations.

\section{B. Competency Development}

Researchers and working panel participated in focus group to develop competency related with functional analysis technique for multimodal transportation management as following.

1. Define key functions of multimodal transportation management.

2. Propose unit of competency (UOC) and element of competency (EOC).

3. Elaborate performance criteria (PC) for each element of competency with detailed document, required knowledge and skill as well as desirable outcome.

4. Allocate the level of competency for whole range of multimodal transportation management professionals.

5. Match the competency levels and detail of competency (UOC, EOC and PC).

\section{Data Validation}

The findings from 5 steps in data collection were presented in the format of sequential focus groups among researchers, working panel representatives and endorsers, in order to endorse the accuracy and reliability of the findings. Triangulation among individuals and stakeholders or so called peer debriefing [22] was conducted to validate the findings. After data validation, the result was written in the format of competency and develop the report to submit for press conference with TIFFA and TPQI.

\section{RESUlTS}

Multimodal transportation management composites of 3 key functions;

1. Operating each multimodal transportation offering

2. Managing multimodal transportation services

3. Developing multimodal transportation management

Cascading to units and elements of competency, the findings were shown 10 units of competency (UOC) and 27 elements of competency (EOC) that illustrated in Fig. 3.

Elements of competency (EOC) in multimodal transportation management relate with planning- monitoring \&controlling-evaluating the services of combined modes for UOC of operating multimodal transportation services, managing customer relationship, supplier relationship and information technology for UOC of managing multimodal transportation services, whereas developing service quality and human resource as well as planning and executing for organizational development for UOC of developing multimodal transportation management.

\section{CONCLUSION AND DISCUSSION}

Professional competency is important toward the successful performance of freight forwarding enterprises [23]. Multimodal transportation management in particular, is recognized as a function of freight forwarding, which itself is embedded unit of supply chain management. This research addresses key competency for multimodal transportation management which is currently coming trend of freight 
forwarders [24]. The functional analysis technique was conducted to generate the competency from real working process and select key content to allocate to units and elements of competency for multimodal transportation [25]. Multimodal transportation management in Thailand acquires high level of planning, monitoring, controlling and evaluation according to higher risks from intermodal transfers with multiple modes of transportation [3]. Therefore the competency findings of multimodal transportation management are prioritized with service planning, coordinating and controlling with key service suppliers [26]. Freight forwarders who manage with multimodal transportation need to be strategic planning with sophisticated combination of transportation modes responding to time or cost or flexibility orientation.

To enhance the managing capabilities of multimodal transportation, the information technology related to decision making such as EDI or decision support system is advantage to service performance of multimodal transportation decision [4], [6], [27]-[29]. The seamless connectivity entitle toward multimodal transportation' performance, the selection of suppliers who expertise with the mode of transport and hub networking in the location become key success factor [30], [31]. Considering globalization in logistics business, the application of regulation knowledge, information technology, transportation infrastructure and regulation information to uplift service quality provides company advantage and embed in core competency of today multimodal transportation managers [17], [32].

This study overviews of competency for multimodal transportation management which is part of international freight forwarding. The research was conducted with reliable process of functional analysis validated by triangulation among three relevant stakeholders in logistics industry. The implication from this results can be extended to provide working evaluation and training to develop logistics professionals in area of multimodal transportation. Further development from competency to employee evaluation, training and development and also certification process should be conducted in order to enhance human resource effectiveness for logistics industry in Thailand. This study suggests the key competency of logistics professionals who manage multimodal transportation, however the detail of other functions in supply chain for instance, international distribution, and packaging service are neglected according to resource limitation in this research. Additional focus study should be employed to fulfill the human development need in the growing logistics industry.

\section{ACKNOWLEDGMENT}

This research was fully supported by Thailand Professional Qualification Institute (public organization) (TPQI). The cooperation of research was supported by Thai International Freight Forwarding Association (TIFFA) and International Transport \& Business School (ITBS).

\section{REFERENCES}

[1] T. G. Crainic, "Long-haul freight transportation,"Handbook of Transportation Science, Springer, 2003, pp. 451-516.

[2] H. J. Ko, "A DSS approach with fuzzy AHP to facilitate international multimodal transportation network," KMI International Journal of Maritime Affairs and Fisheries, vol. 1, pp. 51-70, 2009.
[3] R. Banomyong and A. K. Beresford, "Multimodal transport: The case of Laotian garment exporters," International Journal of Physical Distribution \& Logistics Management, vol. 31, pp. 663-685, 2001.

[4] A. Kengpol et al., "The development of a decision support system in multimodal transportation routing within Greater Mekong sub-region countries," International Journal of Production Economics, vol. 140, pp. 691-701, 2012

[5] G. Xiong and Y. Wang, "Best routes selection in multimodal networks using multi-objective genetic algorithm," Journal of Combinatorial Optimization, vol. 28, pp. 655-673, 2014.

[6] M. SteadieSeifi et al., "Multimodal freight transportation planning: A literature review," European journal of operational research, vol. 233, pp. 1-15, 2014.

[7] UNECE. (2009). Illustrated Glossary for Transport Statistics. [Online]. Available: http://www.unece.org/fileadmin/DAM/trans/main/wp6/pdf

[8] F. Southworth and B. E. Peterson, "Intermodal and international freight network modeling," Transportation Research Part C: Emerging Technologies, vol. 8, pp. 147-166, 2000.

[9] Y. Hayuth, "Intermodality, concept and practice: Structural changes in the ocean freight transport industry,"1987.

[10] R. Kurz and D. Bartram, "Competency and individual performance: Modelling the world of work," Organizational Effectiveness: The Role of Psychology, 2002.

[11] R. J. Mirabile, "Everything you wanted to know about competency modeling," Training and Development, vol. 51, pp. 73-77, 1997.

[12] L. M. Spencer et al., Competency Assessment Methods: History and State of the Art, Hay/McBer Research Press, 1994.

[13] L. E. Gale and G. Pol, "Competence: A definition and conceptual scheme," Educational Technology, vol. 15, pp. 19-24, 1975.

[14] R. Boam and P. Sparrow, Designing and Achieving Competency: A Competency-Based Approach to Developing People and Organizations, McGraw-Hill Book Company Limited, 1992.

[15] D. C. McClelland, "Testing for competence rather than for"intelligence," American psychologist, vol. 28, pp. 1, 1973.

[16] Center on Education and Training for Employment. The Ohio State DACUM Process. [Online]. Available:www.http://dacum.osu.edu/

[17] P. R. Murphy and R. F. Poist, "Skill requirements of contemporary senior-and entry-level logistics managers: A comparative analysis," Transportation Journal, pp. 46-60, 2006.

[18] V. V. Thai, "Competency requirements for professionals in logistics and supply chain management," International Journal of Logistics Research and Applications, vol. 15, pp. 109-126, 2012.

[19] S. Elzarka et al., "Creating a logistics competency framework for Egyptian clothing companies," Logistics Research Network LRN 2008.

[20] K.-C. Shang and P. B. Marlow, "The effects of logistics competency on performance,"2007.

[21] V. V. Thai, "Competencies required by port personnel in the new era: conceptual framework and case study," International Journal of Shipping and Transport Logistics, vol. 4, pp. 49-77, 2012.

[22] J. W. Creswell, "Five qualitative approaches to inquiry," Qualitative Inquiry and Research Design: Choosing among Five Approaches, pp. 53-84, 2007.

[23] Y. -H. Cheng and C.-Y. Yeh, "Core competencies and sustainable competitive advantage in air-cargo forwarding: evidence from Taiwan," Transportation journal, pp. 5-21, 2007.

[24] W. Dewitt and J. Clinger, "Intermodal freight transportation," Transportation in the New Millennium, 2000.

[25] R. M. Harris et al., Competency-Based Education and Training: Between a Rock and a Whirlpool, Macmillan Education AU, 1995.

[26] K.-H. Lai, "Service capability and performance of logistics service providers," Transportation Research Part E: Logistics and Transportation Review, vol. 40, pp. 385-399, 2004.

[27] A. E. C. Mondragon, et al., "Facilitating multimodal logistics and enabling information systems connectivity through wireless vehicular networks," International Journal of Production Economics, vol. 122, pp. 229-240, 2009.

[28] I. Harris et al., "ICT in multimodal transport and technological trends: Unleashing potential for the future," International Journal of Production Economics, vol. 159, pp. 88-103, 2015.

[29] P. R. Murphy and J. M. Daley, "International freight forwarder perspectives on electronic data interchange and information management issues," Journal of Business Logistics, vol. 17, pp. 63 , 1996.

[30] Y.-Y. Song et al., "Strategic alliances in logistics outsourcing," Asia Pacific Journal of Marketing and Logistics, vol. 12, pp. 3-21, 2000.

[31] J.-P. Rodrigue and T. Notteboom, "The terminalization of supply chains: reassessing the role of terminals in port/hinterland logistical relationships," Maritime Policy \& Management, vol. 36, pp. 165-183, 2009 . 
[32] M. Faghfouri, "International regulation of liability for multimodal transport," WMU Journal of Maritime Affairs, vol. 5, pp. 95-114, 2006.

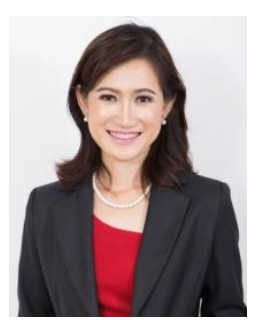

Anothai Ngamvichaikit was born in Bangkok on 27 August, 1973. She got the bachelor degree in pharmaceutical science from Chulalongkorn University, Bangkok, Thailan in 1999; master degree in marketing from Thammasart University, Bangkok, Thailand in 2003, PhD in management from Asian Institute of Technology, Pathumthani, Thailand in 2013.

She is now working as faculty member in Management Science Faculty, Sukhothai Thammathirat Open University, Thailand. She experiences many years as a manager, lecturer and consultant in the pharmaceutical and health care service industry. Her papers has been published in International Journal of Pharmaceutical and Healthcare Marketing (High commended paper award), Managing Service Quality, Journal of Modern Management. Her published book is Buddha Marketing (Bangkok, Ruankaew, 2015) and Market Research (Nonthaburi, STOU, 2016). Her research interest falls in the area of service marketing, SMEs, communication and healthcare organization management.

Dr. Anothai Ngamvichaikit has been awarded with high commented paper in the work of "Communication Need of Medical Tourists" paper from Emerald publishing in 2015. 